\title{
CULTURA VISUAL, ENSINO DA ARTE E COTIDIANO: HIBRIDISMOS E PARADOXOS
}

\section{MIRELA RIBEIRO MEIRA}

URSULA ROSA DA SILVA

\section{Resumo}

O ensino da arte nas escolas enfrenta uma provocação instigante, para o professor, a saber: como trabalhar as questões e as imagens do cotidiano. A Cultura Visual pode, no campo da arte, apontar para uma aproximação entre a vida, com seus paradoxos, o cotidiano, com seus hibridismos, e a escola, com seus desafios. No encaminhamento de uma reflexão para as possibilidades deste ensino, trazemos a contribuição de autores como Merleau-Ponty, Nicolas Bourriaud, Michel Maffesoli, e ainda, Edgar Morin, que baliza a necessidade de um pensamento complexo para pensar uma realidade complexa, de entrecruzamento de fronteiras, hibridismos, incertezas e contradições que, por isto mesmo, permite diálogos fecundos entre a Arte, a Educação e a Cultura.

Palavras-chave:

Cultura Visual, ensino de arte, estética do cotidiano 


\title{
VISUAL CULTURE, ART EDUCATION AND THE EVERYDAY: HYBRIDISMS AND PARADOXES
}

\author{
MIRELA RIBEIRO MEIRA \\ URSULA ROSA DA SILVA
}

\begin{abstract}
Art education in school faces instigating and provocative challenges, for instance, the teacher confronts: how to work with everyday issues and images. In the art field, Visual Culture can point to approximations between life, its paradoxes, the everyday, its hybridism and school, with its challenges. In considering the possibilities of teaching art, we discuss the contributions of authors such as: Merleau-Ponty, Nicolas Bourriaud, Michel Maffesoli, and also, Edgar Morin, who calls for the necessity for complex thinking when thinking about a complex reality of crossed borders, hybridisms, uncertainty and contradictions that, for this very reason, permit rich dialogues between art, education and culture.
\end{abstract} aesthetics of the everyday. 
O pensamento só é interessante quando é perigoso. Perigoso para a opinião consagrada e ronronante que serve de fundamento a todos esses pareceres de especialistas em que se refestela o poder. Tagarelice tonitruante. Jargão enlouquecido fazendo as vezes de pensamento. São cada vez mais numerosos os que nada tem a dizer e o dizem em voz alta. É, com efeito, o que tende a dominar. Repulsiva vulgata em que se comprazem a mediocridade e a midiacracia unidas num espasmo incestuoso.

Michel Maffesoli

La vida personal, la expresión, el conocimiento y la historia avanzan oblicuamente, y no directamente, hacia fines o hacia conceptos. Lo que se busca demasiado deliberadamente, no se consigue.

Maurice Merleau-Ponty

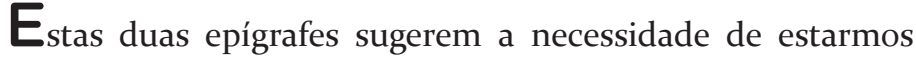
atentos às mudanças, às rupturas e hibridismos que nosso momento sugere. Vivemos uma época de paradoxos: catástrofes, desastres, desesperança, mas igualmente de crença no humano, na construção de processos de dignificação da vida, no estabelecimento de uma ética planetária. Frente aos paradoxos da vida, oscilamos, ora para um lado, ora para outro, buscando referências, processos, teorias, saberes, imagens, que façam sentido para nós.

Em nossa prática de educadoras, percebemos, cotidianamente, tais buscas também em nossos alunos, atônitos com a velocidade, a mutação, a intensidade do movimento das plataformas sobre as quais nossas certezas se assentam. No Curso de Licenciatura em Artes Visuais onde atuamos presenciamos o conflito de nossos alunos frente ao Estágio nas escolas, experiência que envolve muitas expectativas. 
Um dos temas de interesse que tem se evidenciado nos estagiários em trabalhar na sala de aula é como se dá a construção da subjetividade e dos processos de identificação de seus alunos por meio das imagens e da Cultura Visual, quais delas fazem parte de seu cotidiano, como podem interferir na constituição subjetiva. Estas questões tornam-se urgentes quando entram em contato com o ensino de arte de forma mais direta, na escola, e percebem que precisam conhecer mais do cotidiano de seus alunos para planejarem suas aulas. Uma possibilidade de resposta a essas perguntas tem lhes sido frequente após diagnósticos iniciais na sala de aula e, observando os alunos, sondam seu conhecimento prévio: imagens da mídia, do mercado de consumo, roupas e objetos de personagens da moda; programas de TV; celulares ou computadores de última geração; carros; shopping, ou seja, uma relação direta com consumo, de um lado, e com objetos, coisas que, aparentemente, precisam se apropriar para se sentir com uma identidade, de outro. Não só estes objetos, mas igualmente as imagens que os cercam, bem como a construção do desejo de possuí-los são marcantes na construção dos processos de identificação, que são, diferentemente da modernidade, fluídos, caleidoscópicos, mutantes, compostos de vários "eus", afirma Michel Maffesoli (2001), pensador francês. Para ele, nossas identidades, processuais, são construídas de forma fragmentada, em um mundo onde a globalização e o multiculturalismo, decorrente desta, aliam-se à incerteza do momento pós-moderno. O consumo, o tempo acelerado, o excesso de informações a que somos submetidos diariamente passa a nos definir como integrantes de um mundo contectado, interligado, fugaz, caótico, de mudanças por vezes desconcertantes. Em nosso cotidiano, as imagens decorrentes destas mudanças desempenham um papel que, muitas vezes, nos escapa. Compreender o vitalismo destas imagens a partir de um campo amplo e complexo, como o da Cultura Visual, passa a ser, então, um passo de extrema importância para a educação, especialmente para a educação em arte. Especialmente se quisermos trabalhar de forma crítica, valorizando a cultura do outro, escapando às hegemonias que enfatizam "conteúdos curriculares indubitavelmente eurocêntricos e norte-americanos, formalistas e modernistas" e não tratam de forma suficiente "as realidades, os contextos e as subjetividades pelas quais os estudantes veem, visualizam e constroem seus universos" (DIAS, 2012, p.58). 
Há uma extraordinária explosão da imagem pós-moderna, afirma Michel Maffesoli (1995), que recomenda saber reconhecer nela um saber direto, uma partilha de experiências, de modos de vida e maneiras de ser. Ela é vetor de conhecimento, religante, empática, agregadora, e faz parte da construção dos processos identitários. Esta constituição - ética e estéticapassa pela Cultura Visual, que passa a ser um referencial que implica na conduta das pessoas, influenciando toda uma rede de elementos simbólicos da atualidade.

Segundo Hernández (2007, p.27), pesquisador espanhol, o papel da Cultura Visual é observar a "relevância que as representações visuais e as práticas culturais tem dado ao 'olhar' em termos das construções de sentido e das subjetividades no mundo contemporâneo". Sugestões sensoriais das mídia, por exemplo, criam uma realidade artificial que se difunde por imagens e textos em um mundo virtual que se agiganta e que é preciso, cada vez mais, saber como articular seus elementos, superando as inculcações, estereotipias e massificações que as tecnologias criam.

Herdamos da tradição europeia uma civilização autorreferente, racionalista, em que a prevalência do conceito, da objetividade, longe de se tornarem erradicados, ainda são espectros na construção de saberes. Esta crítica ao pensamento da tradição foi feita em meados dos anos 1940 por Merleau-Ponty, filósofo francês, momento inicial da história revisar suas concepções de sujeito e da história da arte reconhecer a historicização de imagens para além das artes clássicas fundadas na forma perfeita. A visualidade da arte, para este filósofo, é um modo de tratar da percepção a partir de um olhar do artista para a natureza desde seu modo de estar no mundo, seus significados, sua expressão originária por meio da obra, conferindo à arte uma espécie de base para o conhecimento sensível. Na Fenomenologia da Percepção, identifica uma racionalidade estética própria ao corpo-sujeito ou o corpo-próprio. Essa concepção de corporeidade aponta para um humano ambíguo, híbrido, sujeito e objeto ao mesmo tempo, ou seja, que olha e pode ser olhado, é sujeito do conhecimento e também passível de ser conhecido. Merleau Ponty (2006; 1989a) relaciona o campo de conhecimento da arte como um exemplo do modo originário de olhar para o mundo que começa na visualidade e na gestualidade que vê com todo o corpo, antes da elaboração do conceito. A percepção, através da relação com o mundo e as imagens, é o modo primeiro de consci- 
ência do que nos cerca, para a posterior ideia ou representação das coisas:

A visão do pintor não é mais um olhar sobre um exterior, relação 'físico-ótica' somente com o mundo. O mundo não está mais diante dele por representação: antes, o pintor é que nasce nas coisas como por concentração e vinda a si do visível; e o quadro, finalmente, não se refere ao que quer que seja entre as coisas empíricas senão sob a condição de ser primeiramente 'autofigurativo'; ele não é espetáculo de alguma coisa a não ser sendo 'espetáculo de nada', rebentando a pele das coisas para mostrar como as coisas se fazem coisas e o mundo se faz mundo (1989 a, p.66).

O modo de ver do pintor é o exemplo do momento originário do conhecimento, em que não apenas o cientista pode experienciar, mas podemos, todos, experimentar a mesma relação com o mundo, um pertencimento que nos permite ver, conhecer e expressar. É crucial aprender a ver, estar aberto para a eterna novidade do mundo, ao novo que se instaura nos significados que já estão aí. Nesse sentido, Merleau-Ponty nos desafia a criar novos significados, novas formas de viver/ estar neste mundo paradoxal, pós-moderno, de hibridismos, multiplicidade de informações que abarrotam nosso cotidiano, de excessos e incertezas.

Assim, a possibilidade de criar e de atribuir novos significados ao mundo é tão infinita quanto nossa capacidade de perceber e expressar novos sentidos, mesmo que 'tudo', aparentemente, já tenha sido produzido e dito. Uma questão, aqui, se sobressai: como o professor de arte pode usar este 'tudo' que nos envolve cotidianamente, levando para a sala de aula, e trabalhar a consciência crítica e a sensibilidade estética através e para com as imagens? Se nosso cotidiano nos tem levado a consumir imagens- e tantos outros produtos- a ponto de nossa própria identidade se ligar diretamente aos objetos a nosso redor.

A este respeito, observa Nicolas Bourriaud (2009, p.1112), teórico francês, que o cotidiano, o espaço das relações habituais, é o mais duramente atingido por um empobrecimento e uma reificação gerais, pois, "[...] perante as mídias eletrônicas, os parques recreativos, os espaços de convívio, a proliferação dos moldes adequados de socialidade, vemo-nos sem recursos", longe do sujeito ideal "da sociedade dos figurantes", reduzidos assim a um "[...] consumidor de 
tempo e de espaço, pois o que não pode ser comercializado está fadado a desaparecer". Se quisermos escapar da previsibilidade, nossas relações, simbolizadas ou substituídas por mercadorias, "[...] precisam assumir formas extremas ou clandestinas, uma vez que o vínculo social se tornou um produto padronizado".

Desta forma, enfrentamos um paradoxo: temos uma capacidade infinita para criar novos sentidos, mas muitas vezes a 'coisificação' que nos envolve no mundo de consumo de objetos, imagens, modos de vestir, comer e até mesmo pensar, nos impede de sair da mesmice, e, como ratos de laboratório, nos auto condenamos a um percurso invariável em nossas gaiolas. A coisificação geral, ao mesmo tempo em que atinge as relações humanas e torna tudo passível de ser consumido como objeto, permite encontrar as brechas que permitam escapar à regulação do mercado. Uma das brechas é a compreensão de que o mundo não está dado, pois “[...] não existem formas na natureza, no estado selvagem, porque é nosso olhar que as cria, recortando-as na espessura do visível" (BOURRIAUD, 2009, p. 30). A arte tem sido, de certa forma, segundo ele, poupada desta regulação excessiva, na medida em que, além da prática artística aparecer como “[...] um campo fértil de experimentações sociais" e "um espaço parcialmente poupado à uniformização dos comportamentos", ela não possui uma "essência imutável", mas, antes, é um "jogo cujas formas, modalidades e funções evoluem conforme as épocas e os contextos sociais" (idem, p.13-15). A partir desta reflexão, a arte alcança elementos de dissidência para a Cultura Visual, que tem sido um ponto de partida para análise de imagens e, mais recentemente, no ensino da arte na sala de aula.

Nicolas Mirzoeff (2003, p.52) levanta questões entre a visualidade e o consumo ao assinalar que a experiência transcultural do visual na vida cotidiana tem lugar no território da Cultura Visual: "[...] la experiencia visual es un acontecimiento que resulta de la intersección entre lo cotidiano y lo moderno que tiene lugar a través de las 'líneas tortuosas' marcadas por los consumidores que traspasan las redes de la modernidad. (...) El consumidor es el agente clave de la sociedad capitalista posmoderna.

Deste modo, não se trata apenas de identificar a origem das imagens ou de que modo surgem e participam de nosso cotidiano, mas saber como este se caracteriza, para além dos moldes através dos quais fomos ensinados a pensar. Precisamos 
transcender estes modelos, aprofundando questionamentos sobre a visualidade contemporânea, se quisermos sair da mesmice que observamos no ensino de arte nas escolas onde atuamos, centrado na releitura de obras da História da Arte que chegam, quando muito, até o período das vanguardas. Para tanto, é preciso mergulhar num mundo de significados anteriores à própria imagem, entender o campo ético-estético e político que a cerca, suas implicações em nossos cotidianos, que valores e sentimentos incitam determinados comportamentos, como os consumistas, por exemplo, e as consequências implicadas neste universo. É aqui que a Cultura Visual contribui para localizar, também, o contexto de geração e consumo de imagens, para relacionar as imagens com cada modo de expressão- e podemos localizar sua importância para o ensino da arte a partir de uma perspectiva ampla, multicultural. Justamente o sentido de cultura, para Mirzoeff (2003, p.49), tem como propósito enfatizar que "[...] la cultura es el lugar en el que las personas definen su identidad y eso cambia de acuerdo con las necesidades que tienen los individuos y comunidades de expresar dicha identidad".

Fernando Hernández (2010, p.77) caracteriza o campo da Cultura Visual como

[...] (a) um campo de estudo que indaga sobre as práticas de olhar e os efeitos do olhar sobre quem olha; (b) um guardachuva sob o qual se incluem imagens, objetos e artefatos do passado e do presente que dão conta de como vemos e somos vistos; e (c) uma condição cultural que, especialmente na época atual, marcada por nossas relações com as Tecnologias de Informação e Comunicação (TICs), afeta o modo como vemos a nós mesmos e ao mundo.

Trata-se de entender os modos culturais de ver e ser visto, como diria Merleau-Ponty, identificando as práticas de olhar, os modos de perceber o mundo conforme cada lugar, cada comunidade e cada grupo cultural, diria Maffesoli, de entender nossas especificidades culturais e o que nos aproxima como humanos habitantes do mesmo planeta, afirmaria Edgar Morin (2005). Este propõe o desenvolvimento de uma ética de responsabilidade com o que construímos a partir da compreensão do paradigma de disjunção/redução dominante nos modos de conhecimentos a que temos sido submetidos. Para, assim, entender nossas singularidades de humanos na identificação tanto dos antecedentes quanto 
nas aspirações e destinos que podem ser comuns à superação da barbárie, na resistência à crueldade. O que pode se dar a partir da relação com o outro, numa relação estética, vivida como "[...] alegria, embriaguez, comemoração, gozo, volúpia, delícia, encantamento, fervor, fascinação, beatitude, deslumbramento, adoração, comunhão, entusiasmo, exaltação, êxtase" que nos leve a alcançar o sagrado, "[...] um sentimento que aparece no apogeu da ética e do poético" (MORIN, 2005, p. 202). Sentimento este que permita superar o que na modernidade foi pensado a partir da razão para administrar/expurgar a desordem, endereçando-a a lugares periféricos, marginais, para, assim, controlar suas forças de dispersão. A modernidade, assim, demarcou como marginal tudo o que estivesse fora de lugar, como a arte, o mito, a desrazão, a imagem. Modernidade esta que, para Bourriaud (2011, p.13), ainda não acabou, pois às noções modernas de "vanguarda, universalismo, progresso, radicalidade" não é necessário tornar a aderir para "[...] dar um passo além das linhas pós-modernas". Segundo ele, os artistas já deram esse passo. Ao utilizarem em sua prática princípios como "[...] o presente, a experimentação, o relativo, o fluido", desvelam um compromisso com uma cultura mundial. Paradoxalmente, porém, precisam se opor ao que denomina de "[...] nivelamento político chamado globalização"; para que essa cultura emergente "[...] possa brotar das diferenças e singularidades, em vez de se alinhar à padronização vigente, ela terá de desenvolver um imaginário específico" (2011, p.15) e não seguir a lógica globalizante do mercado de consumo.

Isso nos lembra que cada civilização possui um pensamento racional, empírico, técnico e também um saber simbólico, mitológico e mágico, valores que lhe são intrínsecos. Dor, prazer, amor, não podem ser quantificados, e sim metaforizados, poetizados, paradoxais por natureza. As qualidades de algo se expressam por imagens que passam pela hibridização do conhecimento mitológico e poético. $\mathrm{O}$ homem, que se quer sapiens, ao querer regular seu lado demens, na ânsia de domesticá-lo, acaba por expurgá-lo, acarretando em mais barbárie. "Homo demasiado sapiens torna-se, ipso facto, homo demens" (MORIN, 2002, p. 119). O que serve de ligação entre estes é a afetividade: "[...] a vida humana necessita da verificação empírica, da correção lógica, do exercício racional da argumentação. Mas precisa ser nutrida de sensibilidade e de imaginário" (idem, p. 122). Por isto a estética é transfiguradora, atua em uma zona híbrida 
de colaboração simultânea com o pensamento mitológico e o racional, os ultrapassa em seu surrealismo, situa-se na confluência "[...] onde se fecundam os dois pensamentos, o mítico e o racional, os dois universos, o real e o imaginário" (idem, p. 148).

\section{Emitir Paradoxos: Estética e Poder}

Michel Maffesoli (2001) propõe como uma forma contemporânea de pensar, que afirma ser sua capacidade de emitir paradoxos. Paradoxos são figuras muito presente na produção de artistas contemporâneos, como Ligia Clark, por exemplo, quando propõe, tendo o corpo como suporte, a impossibilidade de sentir através do bloqueio de sensações corriqueiras. Assim, uma luva, ao impedir a mão de sentir, recupera "a consciência do sentimento, da percepção, como forma de conhecimento do mundo, como perspectiva da razão". Bloquear, e não "[...] estimular a sensação torna-se sua estratégia recorrente" (FABBRINI, 1994, apud DIAS, 2010, s/p). Demanda admitir que percebemos o mundo a partir de uma implicação emocional, empática, e não racional, base do que Maffesoli chama de socialidade, desenho que fala de uma lógica conflitiva presente no social que coloca em jogo seu contrário, numa perpétua tensão entre sua injunção fundadora e sua disjunção destrutiva, chamada de transfiguração do político: "a paixão, enquanto base do poder, é estética, jogo"( MAFFESOLI, 1997, p.23). Esta depende de uma ética, de um estar-junto capaz de gerar uma identificação estética que integra "[...] todos os aspectos passionais, francamente ilógicos em ação na natureza humana (idem, p.182).

A dimensão ético-estética no social, para este autor, assegura um equilíbrio contraditorial na forma do orgiasmo, energia ritualizadora do caráter destruidor da sombra, misto de sentimentos, paixões, imagens e diferenças que incita a relativizar toda e qualquer normatividade e remete à multiplicidade de experiências coletivas. Esta energia fundadora, arcaica, na constituição da unidade profunda das coisas recusa padrões impostos, regras estilísticas e convenções representativas que se corporificam na imagem pós-moderna. Esta, híbrida, é uma mistura insólita de elementos visuais heterogêneos que negam qualquer convenção, hierarquização ou regulamentação impeditiva de misturas de elementos nas manifestações visuais contemporâneas. 
As imagens híbridas rompem com uma forma única de representação, combinam possibilidades, diversificam atributos visuais, como mixagens de fotos com desenhos, impressos, gravuras etc. De forma metafórica, acontecem também no social e no cotidiano, onde eventos de forte carga emocional, adquirem um novo estilo, no qual "[...] a imagem, o simbólico, o imaginário, a imaginação voltam à cena [compondo] um mundo imaginal" (MAFFESOLI, 1995, p.89). Sua existência constata a necessidade de reconhecer a profusão, o papel, a importância e a pregnância da imagem na vida social. Segundo ele, vivemos numa sociedade iconoclasta, herança judaico-cristã, que nos induz a desconfiar e temer a imagem, a não aceitar a aparência em suas diversas formas, a ter horror dos sentidos, medo à beleza, ódio à matéria. Esta atitude, paradoxal de nossa sociedade, desvela um par antinômico: Dioniso e Apolo. De um lado, um traço apolíneo forte, de ordem, objetividade, razão, representação e verossimilhança da imagem; de outro, um dionisíaco, de desordem, non sense, sensibilidade terrena, de um eterno presente de prazeres. O mundo imaginal configura esta contradição, ao operar, paradoxalmente, "dentro da própria racionalidade que o condena", sendo justamente sua própria irracionalidade que possibilita pensar a razão. Todavia, isso não implica abdicar do intelecto, mas conjurar um saber dionisíaco que integre o caos ou que, pelo menos, conceda-lhe seu lugar na topografia da incerteza e do imprevisível, da efervescência, do trágico e do não racional. Um saber dionisíaco que não justifica ou legitima nada, mas percebe o fervilhar existencial cujas consequências não foram totalmente avaliadas (MAFFESOLI, 1998).

A Cultura Visual participa deste fervilhar da imagem que, relativiza, coloca em relação, re-liga, o que, justamente, a torna suspeita: de provocar fascínio, de arrebatar, tirar o fôlego, colapsar o entendimento, desviar da verdade e do bem, da retidão da razão. A função icônica acompanha o fervilhar da vida, é lasciva, errante, preguiçosa, contentando-se não com o que deveria ser, mas com o que é. Neste sentido, "[...] a imagem constata um elã vital, uma estética emocional em todos os seus afetos, sejam eles refinados, de mau gosto, despojados, kitschs, explosivos ou conformistas" (idem, ibidem, p. 92). É vetor de comunhão, interessa menos por sua mensagem do que pela emoção que faz compartilhar, é orgíaca, ou seja, “[...] passional (orge), estética (...) favorece o sentir coletivo (aisthesis)" (Idem, ibidem,p.93-94). 
Michel Maffesoli anota que o mundo imaginal está substituindo o racional, erroneamente responsabilizado pela brutalização do homem e pelo imoralismo. As imagens seduzem, atraem, e, portanto, "não tem de fazer qualquer injunção moral", assim como a fantasia são "ingovernáveis, desordenadas e um tanto selvagens" (1995, p. 98). Todavia, só fazem sentido no social, de onde extraem sua força ao unir sensibilidade e entendimento.

Vivenciamos o cotidiano não como história, mas "evento" (MAFFESOLI, 1995, p.110-11): É próprio dele "estar ligado ao fenômeno que atualiza, que visualiza", e que "precisa ser visto, [pois] ele é, por construção, imagem, ele se torna visível (...) [e assim] a partilha da imagem, a estética que isso suscita, gera a relação, engendra religação". Um eterno presente - embora não se negue a temporalidade - é que convida a imagem, por oposição ao que a Igreja Católica deseja a seus fiéis: penitência hoje, paraíso amanhã.

Os processos artísticos e criadores operam hibridismos que acionam transformações nas práticas e reflexão entre teoria, prática e contexto de vida. E, quando se trata da vida, "a palavra paradoxo volta frequentemente, até mesmo um paradigma do paradoxo poderia ser a chave da compreensão do mundo em gestação" (MAFFESOLI, 2007, p. 133). Este hibridismo, na figura de uma razão sensível propõe que, na educação, se trabalhe com os fenômenos estéticos da cultura pós-moderna, pensada no presente, nas sinergias da vida, nas atuações, no fazer do ser enquanto in (cons) tituintes. Incluindo a imagem, os artefatos visuais, obras, processos, eventos, para compreender a (com) vivência, apreendê-la em sua complexidade, na dimensão profunda do que vibra muitas vezes em silêncio, na pausa, no em aberto ou subentendido. Expondo a possibilidade de um fenômeno por seu sentido, a realidade, mesmo a da imaginação, se faz mundo, possibilita re-ligar vida e teoria para farejar, intuir, atentar ao instituinte, ao subterrâneo. A hibridação possível entre referenciais raciopoéticos, sistematizados sem uma linearidade rígida, supõe in-venire, trazendo à luz o entusiasmo, a iluminação empenhada em compreender fenômenos, ações e representações humanas pelo que estão, apontando uma ética e uma sensibilidade generosas (MAFFESOLI, 2001). É condição de possibilidade da existência e do conhecimento em sua plenitude, onde a emoção entusiasma a razão a procurar novos pensares distantes da rabujice conceitual, envolvidos num aqui e agora complexo, indiscernível, mas observável na fractalização de suas partes: a interação humana. 


\section{Hibridismos Pedagógicos: Arte e Educação Estética}

O fazer da Arte envolve mente, corpo, interações, afecções, implica numa sensibilidade humana aprendente, que toca o cerne da condição humana vivente e vivida. Qualquer processo pedagógico, especialmente em arte, deve prever um processo ético e estético, em que a imprescindibilidade da experiência é fundamental a qualquer ação que os envolva. A educação estética não se limita aos padrões estabelecidos de gosto, mas diz da existência efetivo-afetiva dos humanos. Neste sentido, é um grande campo híbrido, complexo, no qual a experiência humana alcança um alto grau de realização.

O homem em sua existência modifica a natureza criando produtos culturais, e a Arte é essencial a esta experiência, revelando, mediante imaginação, razão, intuição e sensibilidade, como conjuramos formas de comunicação e expressão, dando forma a ideias. Representa um elo entre a vida cotidiana das pessoas e os símbolos correlacionados, tanto para quem a produz quanto para quem a aprecia. Somos seres simbólicos, capazes de inventar formas interpretando e ordenando o mundo por meio de representações, tenham estas sentido imediato ou não.

Mais especificamente na escola, o desafio do professor em trabalhar com imagens e processos de criação artística e estética é que estas mobilizam saberes e operações complexas no manuseio da fantasia e de repertórios conceituais. Incidem sobre mundos internos e externos com os quais os agentes de transformação pedagógica estão imersos, além de apresentar problemas de escolhas para lidar com interinfluências visuais, comportamentos, gestos criadores e transformações de caráter ético, estético, poético e político, transversalmente às vivências cotidianas. $\mathrm{O}$ trabalho com a imagem conjura valores, reelaborações, interfaces e relações que formam um cosmo de saberes e intensidades, ao buscar-se qualificar a experiência humana por obras, processos e práticas que influenciam a visão e as formas de compreensão da vida social.

O desafio para atualizar a compreensão da arte, no entanto, está no plano de suas virtualidades e dos procedimentos que a constituem. A criação de uma obra vê-se hoje confrontada com estratégias tecnológicas visuais de grande impacto sobre o ambiente vital da cultura. Trabalhar com imagens e processos de criação é simultaneamente aprendizagem construída e vivências de intersubjetivação 
presentes nas experiências de conceber, processar e articular formas, gestos, forças e dramática poético-estética. As afecções são concebidas nas fontes de trabalho e intermediação artificial criadas sob várias intenções de propagação e contaminação social.

\section{Cultura Visual na escola: trabalhando imagens do cotidiano}

Ao propor um debate sobre a pós-modernidade na América Latina, Nestor Canclini, pensador latinoamericano, entrelaça processos de recepção e apropriação de bens simbólicos no que chama de "culturas híbridas", resultante da combinação de várias ciências, como a Antropologia, a Sociologia, a Arte e os estudos das comunicações. Assinala que a visualidade pós-moderna encena uma dupla perda: do roteiro e do autor, e é testemunha da descontinuidade do mundo e dos sujeitos, e do borramento de fronteiras. É zona de cruzamentos, onde as iniciativas sociais escapam aos $p a-$ radigmas clássicos que, ao explicar a dominação, são incapazes de dar conta "da disseminação dos centros, da multipolaridade das iniciativas sociais, da pluralidade de referências - tomadas de diversos territórios - com que os artistas, os artesãos e os meios massivos montam suas obras" (CANCLINI, 1997, p. 329). Hoje, todas as culturas são de fronteira, todas as artes se desenvolvem em relação com outras artes. Um território "ecosófico", ou uma "articulação ético-política entre o meio ambiente, o social e a subjetividade", na tentativa de reconstruir um território político perdido, destroçado pela violência desterritorializante do capitalismo mundial integrado, para Bourriaud (2009, p.142-3). A arte, aqui, define-se como um lugar de importação de métodos e de conceitos, uma zona de hibridações, oferecendo uma espécie de "direito de asilo" imediato a todas as práticas que se distanciam da norma.

Nicolas Mirzoeff (2003) trata a Cultura Visual como uma zona híbrida, multidisciplinar, atravessadora de domínios variados, artísticos, científicos e tecnológicos. A imagem é uma constante, especialmente frente aos processos da virtualidade, hoje, globais.

Podemos tomar como exemplo uma experiência que fizemos na Universidade Federal de Pelotas, em uma oficina de criação a partir de imagens da internet ${ }^{1}$. A proposta da autora surgiu na Licenciatura em Artes e foi aprofundada no Curso de 
Especialização em Artes, relacionando imagens do Orkut, Cultura Visual e identidade. A proposta era buscar novas formas de tratar as imagens, fazer com que os alunos percebessem seu potencial criador a partir de um repertório dado pela mídia, e o quanto cada um pode ir além das marcas, dos estereótipos, produzindo arte de modo criativo, consciente e crítico.

Nas ilustrações abaixo podemos ver pequenas interferências entre a máquina que fotografa e o outro, que nos olha e é olhado, já produzem efeitos inusitados, como o exemplo da ou com fotografia a partir de inserção de vidros molhados, plásticos amassados, etc., entre o máquina e a pessoa fotografada, produzem efeitos interessantes e provocadores de novas visualidades. Ou a simples projeção de imagens com a participação do corpo dos alunos, em que o aspecto criador pode ou permite desvelar uma expressão própria em cada um. Neste sentido, além do trabalho com a imagem, a expressão do corpo provocam o aluno a pensar na própria participação em sua obra. Remete, também, à possibilidade de se falar em identidade, para além das coisas que nos identificam, para como nós nos compreendemos como identificado com algo, com alguém, com situações, com valores.

Como Merleau-Ponty nos afirma: "o enigma reside nisto: meu corpo é ao mesmo tempo vidente e visível. Ele, que olha todas as coisas, também pode olhar a si e reconhecer no que está vendo então o 'outro lado' do seu poder vidente" (1989a, p.50)

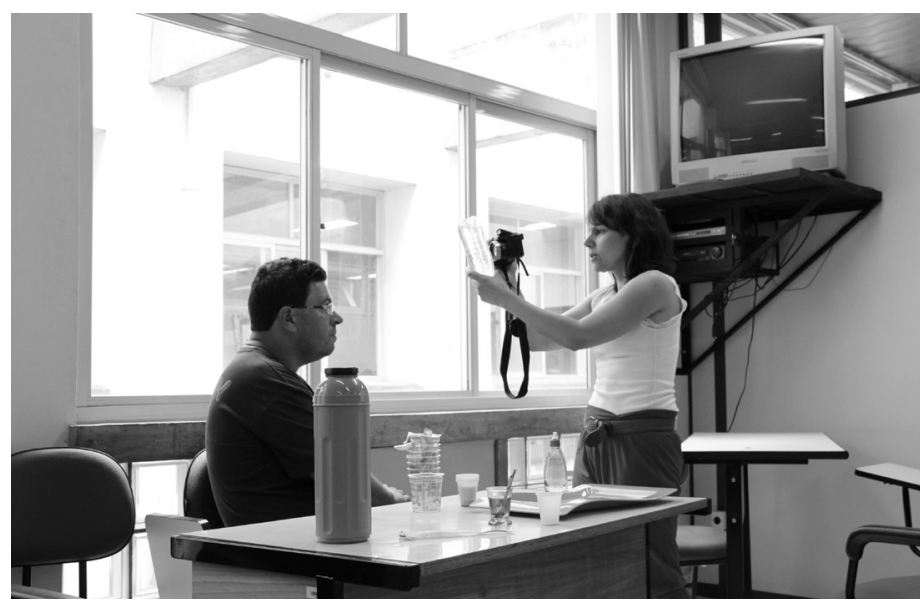

Figura 1: Oficina Maria Valéria. Fotos: Acervo do I Seminário Internacional Ensino da Arte: Cultura Visual, escola e Cotidiano. Pelotas, 2012. 
Figuras 2, 3 e 4: Oficina Maria

Valéria. Fotos: Acervo do I

Seminário Internacional Ensino da Arte: Cultura Visual, escola e Cotidiano. Pelotas, 2012.
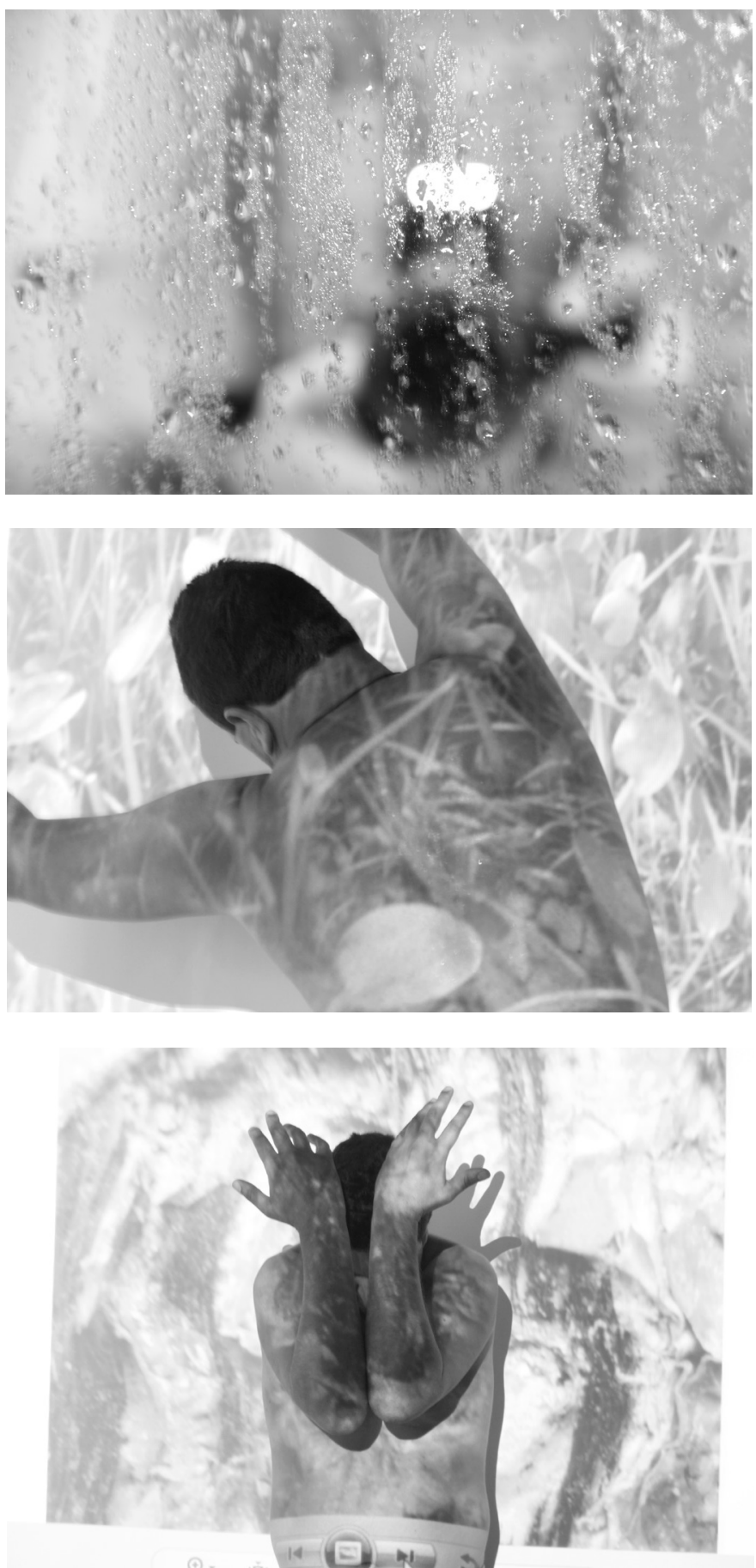
Esta oficina, ao problematizar o imaginário pós- moderno, revela que este, em suas mais variadas manifestações, evidencia que "moda, corpo, ecologia, esporte, música, hedonismo, imagens" são palavras-chave das novas tecnologias do cotidiano. Estas são favorecedoras de "uma criatividade cujo objeto essencial é desfrutar o mundo que se oferece à visão e à vida" (MAFFESOLI, 2007, p. 50), e anunciam o retorno ao apetite das coisas, à comunhão, à re-ligação: seja de paradoxos, hibridismos ou imagens. É que Bourriaud (2009, p.96) afirma ser a função da arte: "apropriar-se dos hábitos perceptivos e comportamentais criados pelo complexo tecno-industrial e transformá-los em possibilidades de vida", subvertendo a autoridade da técnica para torná-la mais capaz de criar maneiras de pensar, ver e viver.

Metamorfoses de imagens de nosso cotidiano permitem uma reflexão capaz de colocar em xeque alguns elementos da arte e seus processos criadores que são parte da Cultura Visual. Esta que, para Mirzoeff, não depende das imagens em si, mas da tendência em colocar em imagens ou visualizar a existência (2003), constituindo uma visualidade própria, distinta em cada época. A Cultura Visual esquiva nossa atenção dos cenários de observação estruturados e formais, como o cinema, o museu, e a centra na experiência visual da vida cotidiana, estendendo-se à tecnologia. Todavia, Bourriaud (2009, p. 92) adverte que, se a informática e a tecnologia da imagem trazem melhorias à vida cotidiana, também "representam ameaças e instrumentos e sujeição". O fundamental é que elas produzam o que chama de "lei da deslocalização", ou, a arte é crítica somente quando desloca seus conteúdos, possibilitando, assim, novas maneiras de ver, ao prover a "consciência dos modos de produção e das relações humanas produzidas pelas técnicas da época" (idem,p.94) , e, através do deslocamento que pode produzir, aumentar a visibilidade de seus efeitos no cotidiano.

Cultura Visual, cotidiano, consumo, arte. O mundo hoje não é mais pós-moderno, é radicante, e a fórmula indicada por Bourriaud para criar neste meio é considerar que

em um universo pós-moderno tudo se equivale. Mas em um universo radicante os princípios se mesclam e se multiplicam por combinatórias: não há mais subtração, e sim incessantes multiplicações. Essa profusão, essa falta de hierarquias claras, combina com essa precariedade que não pode mais se limitar à utilização de materiais frágeis ou a curtas durações, pois que agora impregna o conjunto da produção artística com seus matizes incertos [...] (2011, p. 82-83) 
O ensino de arte na escola precisa, então, considerar esse cotidiano, que acontece fora da escola, mas do qual as pessoas fazem parte, ou melhor, o qual faz parte das pessoas. Não é possível ver alguém por inteiro, entender o aluno, como ele pensa, significa e expressa o mundo, se retirarmos tudo o que o caracteriza no seu dia a dia. Assim, é a partir destas imagens que estão inseridas no olhar e no imaginário destes estudantes que o professor deve elaborar suas ações no âmbito da arte. É tratando da cultura a partir dela mesma, de dentro, desde o que transborda de referenciais advindos da mídia, da televisão, da internet, se utilizando dos suportes mais variados para produzir arte: desde o papel ao celular, não se esquecendo do corpo, que sente, que vibra, que ocupa o espaço, que desenha com gestos no ar, que pinta com dedos, com pés, com pele. E também da natureza, do mundo, de tudo o que nos envolve que também é tema e suporte para criar.

Precisamos da arte, da Cultura Visual, de uma educação da sensibilidade, das sensações, do ver, ouvir, tocar, cheirar, degustar, para, aliados a uma racionalidade mais aberta, possamos melhor compreender as manifestações imagéticas e multiculturais de nosso tempo, o que requer uma postura, mais do que interdisciplinar, transdisciplinar, ou seja, capaz de romper com os disciplinamentos impostos por modelos racionalizantes, sejam éticos, estéticos, epistemológicos ou políticos. E assim, abandonar a rabujice conceitual a que temos sido submetidos e vagabundear em direção a um mundo mais pleno de prazeres em um cotidiano que valha a pena ser vivido coletivamente aqui e agora. Que digam, através da convivência ou da tecnologia, dos mistérios da comunhão de algo que nos ultrapassa, do cum-crescere, crescer juntos. Precisamos, especialmente no campo do ensino da arte e da educação estética, de construções transtemporais que se dirijam à raiz da vida para nela se renovarem ciclicamente, seja no cuidado do que é frágil, impreciso, mutante e vivo, seja na alterização paradoxal do orgiasmo. De qualquer forma, a Cultura Visual é mais uma das possibilidades de reflexão e conexão com o campo mutante, vivo, de novas possibilidades que é o da socialidade humana. Esta, no cotidiano - campo híbrido de razão e paixão - inclui o paradoxo, o conflito, o dissenso. Nele, a imagem permite reter o vivido, epifanizar o cotidiano, remete à sensibilidade que permite viver o que é - e, especialmente através da arte - criar o impertinente, o desmesurado, o barulhento, o prazer, o perigo e o interessante. 


\section{Referências}

BOURRIAUD, Nicolas. Radicante: por uma estética da globalização. São Paulo: Martins Fontes, 2011.

. Estética Relacional. São Paulo: Martins Fontes, 2009.

CANCLINI, Nestor García. Culturas Híbridas. São Paulo: EDUSP, 1997.

DIAS, Belidson. Arrastão: o cotidiano espetacular e práticas pedagógicas críticas. In: MARTINS, R. TOURINHO, I. (orgs.) Cultura das Imagens: desafios para a arte e para a educação. Santa Maria: Ed. UFSM, 2012, p.55-73.

DIAS, Carlos A. A construção do corpo coletivo: A dimensão política da obra de Lygia Clark. In: Panorama. Revista Eletrônica de Arte. №o7, Ago | Set 2010. Disponível em: http://www.panoramacritico.com/oo7/panorama.php. Acesso em 29.04.2013.

HERNÁNDEZ, F. Para a Erina ninguém diz nada... e nós não podemos fazer o que queremos a educação da Cultura Visual na educação infantil. In: MARTINS, R. TOURINHO, I. (orgs.) Cultura Visual e Infância: quando as imagens invadem a escola... Santa Maria: Ed. UFSM, 2010, p.71-85.

. Catadores da Cultura Visual. Porto Alegre: Editora Mediação, 2007.

MAFFESOLI, Michel. O Ritmo da Vida. Rio de Janeiro: São Paulo: 2007.

. Elogio da Razão Sensível. 2 ed. Rio de Janeiro: Vozes, 2001.

Tempo das Tribos: o declínio do individualismo na sociedade de massa. Rio de Janeiro: Forense Universitária, 1998.

A Transfiguração do político. Porto Alegre, Ed. Sulina, 1997.

. A Contemplação do Mundo. Porto Alegre: Artes e Ofícios, 1995.

MERLEAU-PONTY, M. Fenomenologia da Percepção. Rio de Janeiro: Freitas Bastos, 2006.

O Olho e o Espírito. In: Os Pensadores. São Paulo: Nova Cultural, 1989a.

. A Linguagem Indireta e as Vozes do Silêncio. In: Os Pensadores. São Paulo: Nova Cultural, 1989b.

MIRZOEFF, Nicholas. Una Introducción a la Cultura Visual. Barcelona: Paidós, 2003

MORIN, Edgar. O Método 5: A Humanidade da Humanidade.

Porto Alegre: Sulina, 2002. 
NOTA

1 Oficina: Imagens de Orkut, Autorretrato e constituição de subjetividades, ministrada por Maria Valéria Rodrigues Santos (IFSul, Pelotas), no I Seminário Internacional Ensino da Arte: Cultura Visual, escola e Cotidiano, em novembro de 2012, na UFPEl, Pelotas/RS.

Recebido em: 07/10/2013

Aceito em: 08/ 11/2013 
MIRELA RIBEIRO MEIRA

mirelameira@gmail.com

Professora da Faculdade de Educação, no Curso de Pedagogia, e do Mestrado em Artes Visuais da UFPel, onde coordena o Núcleo Transdisciplinar de Estudos Estéticos (NUTREE).

\section{URSULA ROSA DA SILVA}

ursularsilva@gmail.com

Professora do Centro de Artes da UFPel. Em 2011 publicou o livro A Infância do Sentido - ensino de filosofia e racionalidade estética em Merleau-Ponty, resultante de sua tese de Doutorado em Educação. Desde 2010 tem participado na organização de livros com o tema Ensino de Arte, pela Editora da UFPel e vinculados à linha de pesquisa do Mestrado em Artes Visuais da UFPel 